\title{
Association between Knowledge of the Pneumococcal Vaccine, Vaccination Status and Recommendations for Vaccination
}

\author{
Jennifer Beverley ${ }^{1}$ Helen Heacock ${ }^{2}$
}

1 Lead Author, School of Health Sciences, British Columbia Institute of Technology, Burnaby, BC

2 Supervisor, School of Health Sciences, British Columbia Institute of Technology, Burnaby, BC

\begin{abstract}
BACKGROUND

Pneumococcal disease caused by Streptococcus pneumoniae has a high morbidity rate in elderly individuals aged 65 or older. Previous studies have demonstrated that low vaccination rates with the 23valent pneumococcal polysaccharide vaccine (pneumovax) are due to a lack of awareness and knowledge about the vaccine in the general population. This study measured the association between the public's knowledge of the pneumococcal vaccine, vaccination status, the type and number of health care facility visits per participant in the past year and number of advertisements seen for the vaccine.
\end{abstract}

\section{METHODS}

This study used a survey to test the knowledge of its participants on the pneumococcal vaccine and associated the results with nominal data such as vaccination status and recommendation for vaccination by their primary health care providers. The survey tested the participants using 15 true or false questions that assessed their knowledge on the pneumococcal vaccine and pneumococcal disease.

\section{RESULTS}

No association was found between the knowledge individuals have on the pneumococcal vaccine and whether their health care provider recommended the vaccine $(\mathrm{p}=0.467)$. However, a statistical difference in knowledge between individuals who are vaccinated and individuals who are not vaccinated was found $(p=0.039(\mathrm{CHI}), \mathrm{p}=0.011$ (ANOVA)). There was also a positive association found between vaccination status and primary health care provider recommendation for the pneumococcal vaccine $(p=0.001)$. No association was found between vaccination status and number of visits to a primary health care provider in the past year $(\mathrm{p}=0.149)$. Using an ANOVA analysis, it was found that there was a difference in number of advertising types seen for each vaccination status group $(\mathrm{p}=0.011)$.

\section{CONCLUSION}

Based on the results, it can be concluded that individuals who are vaccinated have more knowledge on the pneumococcal vaccine, but their knowledge is not affected by a recommendation to receive the vaccine from their primary health care provider. This suggests that health care providers are not providing sufficient information about the vaccine to their patients when they recommend it. Despite this knowledge gap, the association between vaccination status and primary health care provider recommendation for the vaccine indicates that individuals are more likely to get vaccinated when their primary health care provider recommends it. However, more visits to the provider annually did not influence the vaccination status of the patient. In addition, results from the ANOVA analysis suggest that participants who saw more vaccine advertisements were more likely to be vaccinated.

KEYWORDS: Streptococcus pneumoniae, pneumococcal disease, pneumovax, vaccination, knowledge, advertisements, health care provider recommendation

\section{INTRODUCTION}

Pneumonia is one of the leading causes of death in the elderly. In Canada, the human population is aging at an extraordinary rate and with this increase in elderly citizens, pneumoniarelated healthcare costs are also drastically increasing. Specifically, in British Columbia, over one-quarter of all revenue received from provincial taxes, fees and licenses goes towards health care funding. (1) By providing lifesaving vaccines such as the 23 -valent pneumococcal polysaccharide vaccine (pneumovax), 
pneumococcal-related hospitalization and medication costs can be reduced. This vaccine is provided free to the majority of Canadian citizens aged 65 or older. $(2,3)$ Currently, only $35-40 \%$ of Canadians over 65 have received the pneumococcal vaccination. (4-6) By implementing more programs that promote pneumococcal vaccination, these rates should increase and the quality of life for the elderly can be improved. Since this bacterium is an opportunistic pathogen, it often infects individuals who are immunocompromised or have underlying comorbid diseases. $(5,7,8)$ With a greater awareness of the pneumococcal vaccine, these individuals can be protected from infection directly through vaccination or indirectly through herd immunity. This project will evaluate the knowledge of the Canadian population regarding the pneumococcal vaccine and will determine how information on the vaccine is most commonly disseminated.

\section{Pneumococcal Disease}

Pneumococcal vaccine coverage in the elderly is low compared to other vaccination rates in Canada. (4) Information on the efficacy of pneumovax and the risks associated with pneumonia are useful to educate the public on the advantages of vaccination. With a greater awareness of the pneumococcal vaccine, vaccination rates will increase and herd immunity may be reached. The 23 -valent pneumococcal polysaccharide vaccine protects against 23 serotypes of Streptococcus pneumoniae out of 93 known serotypes. $(5,9)$ The reservoir for this opportunistic bacteria is situated within the human nasopharynx and can be transmitted by direct oral contact or inhalation of respiratory droplets of an infected or colonized person. (2) This bacteria causes approximately $40 \%$ of all community-acquired pneumonia and can lead to sinusitis, bacteraemia and meningitis. (7) The most common sign of pneumococcal disease, pneumonia, is an inflammation of the air sacs in the lungs which presents itself with a variety of symptoms. Severe symptoms may include acute respiratory distress, collapsed lungs, empyema, and abscesses of the lung tissue. (10) Presence of pneumococcal disease in an individual may be diagnosed by the presence or absence of symptoms, positive results of infiltrates on chest X-rays, isolation of Streptococcus pneumoniae from bodily fluids or a positive antibody or antigen result. (9) Treatment of pneumococcal infections depends on the severity of the illness. Typical treatment of bacterial pneumonia involves a week-long course of antibiotics, but more severe cases may need invasive surgery to remove abscesses or to drain the lungs of fluid.

(10) Since Streptococcus pneumoniae infections are known to have a high morbidity and mortality rates in the elderly, it is imperative that the pneumococcal vaccine be widely distributed to help prevent further deaths and reduce associated health care costs. (11)

\section{Distribution of pneumococcal disease and vaccination in the elderly}

Pneumococcal disease incidence is highest in the population aged 60 and older in Canada. $(2,3,6,8,12-14)$ Since the elderly often have underlying comorbid diseases, weaker immune systems and impaired mucociliary clearance, they are at a higher risk of infection from opportunistic bacteria. $(2,3,5-8)$ In British Columbia, the incidence rate of pneumococcal disease in 2014 was 16.6 cases per 100,000 individuals over age 60. (3) This rate is depicted in Figure 1 obtained from the BCCDC Annual Summary of Reportable Diseases. (8) Of these cases, $59 \%$ were serotypes covered by the pneumovax vaccine. (8) In the Fraser Health region, the incidence rate of pneumococcal disease in 2013 was 25 cases per 100,000 individuals. (5) In contrast to the BCCDC findings, the majority of cases reported by Fraser Health were caused by serotypes that are not included in the pneumovax vaccine. (5) In the Greater Vancouver Area, many elderly individuals are moving into group homes or independent living facilities. This increase in individuals over 60 living closely together may facilitate the transmission of pathogenic bacteria. With an increasing aging population, outbreaks of pneumococcal disease may occur at a higher frequency. By increasing vaccination rates with pneumovax, the overall case incidence rate from common serotypes of Streptococcus pneumoniae should be reduced significantly in at risk populations. This increase in vaccination coverage will help create herd immunity among 
those people living in conditions that create more opportunities for transmission of Streptococcus pneumoniae.

Figure 1: Incidence rates of invasive pneumococcal disease in British Columbia per 100,000 in population (3)

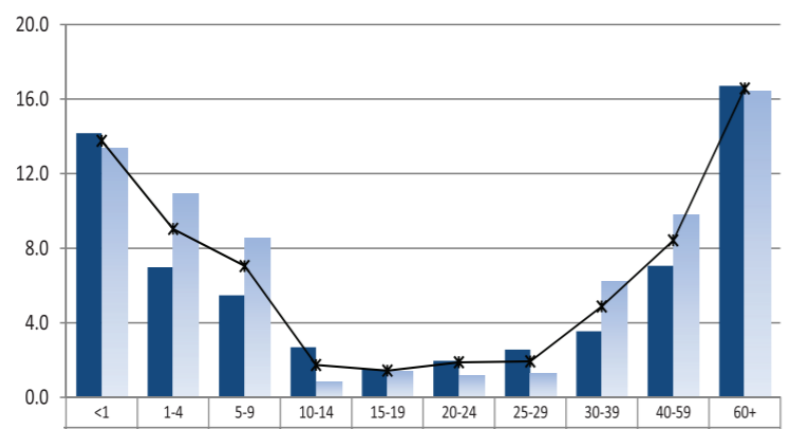

Efficacy of the 23-valent pneumococcal polysaccharide vaccine

The efficacy of the 23-valent pneumococcal polysaccharide vaccine pneumovax is highly controversial. This review used meta-analyses and clinical case studies to attempt to determine the efficacy of the pneumovax vaccine. Depending on the type of study conducted, the results found were widespread and heterogeneous. Inconclusive results were found for many of the metaanalyses, since the studies included both observational and clinical trials and also contained multiple outliers. $(5,9,10,15-17)$ These meta-analyses found that clinical trials showed the vaccine to be ineffective, whereas observational studies showed the vaccine to be effective and cost-efficient. $(9,15,16)$ Studies that examined both the 23 -valent vaccine and the 13-valent conjugated version of the vaccine normally given to children, suggested that the 13 -valent vaccine has a higher efficacy rate in adults and should be subjected to more research. $(9,17)$ Overall, a reduced risk of pneumococcal disease was found in subjects aged 60 or greater within five years of the pneumovax vaccination. $(15,16)$ This reduction in efficacy five years after the initial vaccination could be due to antibody responses being weaker in the elderly as they age or due to a short duration of immunity caused by a decline in antibody concentration. The vaccine is currently only given in one dose and does not require a booster shot. (6) Vaccine efficacy may be increased if a booster shot is given 5 years after the original vaccination, but this would also increase associated health care costs. The uncertainty surrounding the efficacy of the pneumococcal vaccine may be reducing vaccination uptake.

\section{Knowledge of the pneumococcal vaccine in the elderly and how information is disseminated}

Knowledge of the pneumococcal vaccine is disseminated through various pathways such as through primary health care providers, emergency response personnel, nurses, pharmacists, internet searches and word of mouth. It is important to understand the social determinants and factors that influence vaccine uptake so vaccination rates can be improved in the future. The most influential predictor of pneumococcal vaccination and knowledge is recommendation by a general practitioner or family physician. $(13,14,18-24)$ Following recommendation by a physician, the other most influential factors are previous influenza vaccination, family member recommendation, media influence, number of visits to a health care facility and flu clinic advertisements. $(13,14,18-24)$ Social determinants such as an increased number of comorbidities and higher income also increased the probability that an individual was vaccinated. (24) Reasons for nonvaccination included lack of information about the vaccine, high perceived risks and low perceived benefits. (24) Overall, the awareness of the pneumococcal vaccine is low in Canada, and by implementing new public health initiatives, the current knowledge of elderly Canadians will be increased. These public health initiatives should focus on the most influential factors that determine an individual's knowledge. The majority of knowledgeable and vaccinated participants in the reviewed studies had received recommendations from a general practitioner or family doctor. $(7,12,13,18-23)$ Studies conducted in Australia, Germany, USA, Canada, and the Netherlands have shown that approximately $20 \%$ of doctors do not recommend the pneumococcal vaccine to their patients. $(4,12,13,21,22)$ Practitioners may not recommend the vaccine for the following 
reasons: they are too concerned with more immediate health problems when conducting examinations, they perceive the pneumococcal disease as low risk, they have difficulty determining the vaccination status of the patient, they are concerned about negative side effects, or they believe the efficacy of the vaccine is too low. $(4,12,13,21,22)$ To break down these barriers to vaccination, education and public health initiatives involving physicians would be the most effective way to raise vaccination rates.

\section{METHODOLOGY}

This project tested the knowledge of its participants on the 23-valent pneumococcal polysaccharide vaccine. To test their knowledge, 15 true or false questions about the pneumococcal vaccine and pneumococcal disease were asked. The 15 questions were analysed using both numerical data and nominal data. The numerical score out of 15 was analyzed using an ANOVA and post-hoc test. This numerical data was compared with nominal data collected such as vaccination status or recommendation for vaccination. The nominally scored test was analyzed using chi-squared tests. The nominal scores were determined using a system that categorized scores into very knowledgeable, knowledgeable, $50 \%$ knowledge, limited knowledge and inadequate knowledge. Both numerical and nominal results of participant knowledge were used for comparison of statistical significance found.

A survey approach was chosen to collect the data and was self-administered in person or via the internet using Survey Monkey. (25) Previously used questions from surveys reviewed in the literature review for this project were also referred to. Four major malls were randomly chosen in the Metro Vancouver region to hand out surveys and the website link to the online survey. Facebook was also used to distribute the survey. When a participant was approached in-person, a script would be read by the person conducting the survey to engage the individual. A cover letter and consent form was also read and signed by all participants. This project used paper for the survey and provided pens to the participants. Two clipboards were also used to write on so multiple individuals could participate at once. NCSS and Microsoft Excel programs were used for the statistical analyses. $(26,27)$ Google Docs and Microsoft Word were also used for collection of output data from NCSS Statistical Software and the creation of the survey. $(26,28,29)$

\section{Inclusion and Exclusion Criteria}

This survey focused on the knowledge of individuals over 65 who were currently eligible to receive the pneumococcal vaccine for free in Canada, but also included individuals from 21-65. By broadening the inclusion criteria for the age of participants, educational tools and programs could potentially be extended to those who may receive the vaccine in the future. The pneumococcal vaccine is also available free to individuals who have comorbid diseases or are immunocompromised and these people were represented within all age groups. Both vaccinated and unvaccinated individuals were asked to participate, therefore the results were representative of the general population. Also, individuals across Canada were surveyed, therefore this survey asked participants which province they currently lived in. By doing this, results could potentially be extrapolated to the general Canadian population. Another excluded group were friends and family of the person who was conducting the survey. This survey was also only available in English, which excluded any Canadians who did not speak English.

\section{RESULTS}

\section{Description of Data}

This survey incorporated both descriptive and inferential data using Survey Monkey, Microsoft Excel and NCSS statistical software. (25-27) Nominal data was collected on demographic information such as age, gender, and location of residence. Vaccination status, level of knowledge of the pneumococcal vaccine, recommendations for vaccination received and advertisements seen were also collected. Proportions, percentages, charts and graphs were used to represent this nominal data. This data was analyzed using chi-squared tests to assess association between groups. Discrete numerical data collected on the participant's knowledge of the pneumococcal vaccine was analyzed using 
both descriptive and inferential statistics. An ANOVA test was used for this analysis and included means and probability levels.

\section{Results of Descriptive and Inferential Data}

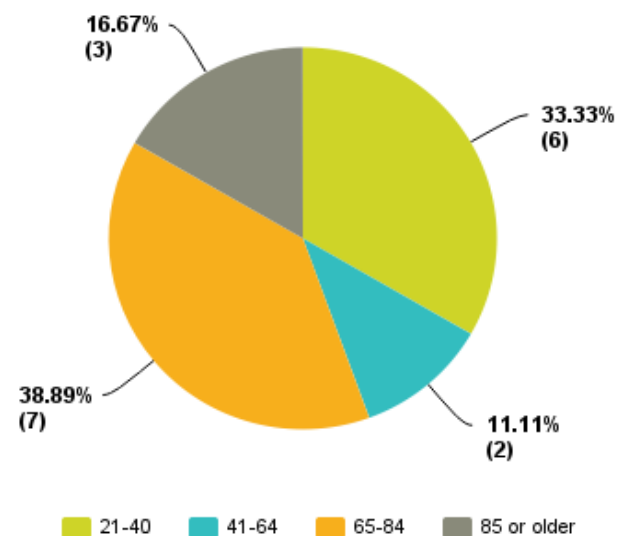

Incomplete surveys were omitted in the descriptive data for recommendations and advertisement seen.

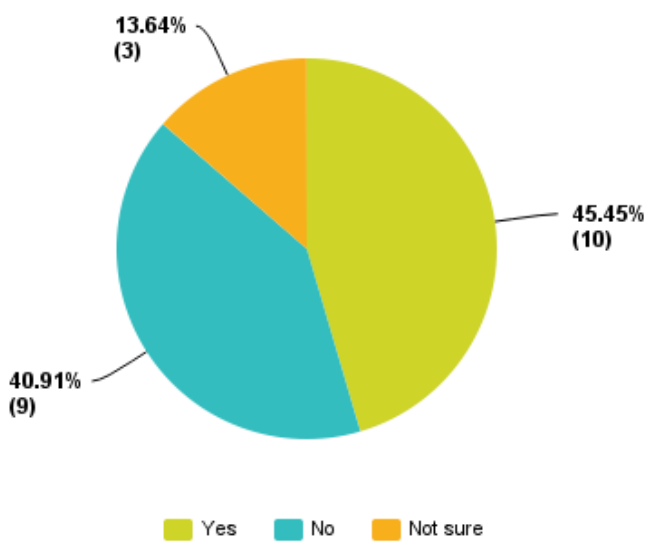

Figure 2. (Left) Age distribution of individuals who were vaccinated with the pneumococcal vaccine Figure 3. (Right) Vaccination status of individuals aged 65 and older

Table 1. Pneumococcal vaccine recommendations to participants $(\mathrm{N}=95)$

\begin{tabular}{|c|c|c|c|}
\hline & Recommended & Not Recommended & Not Sure \\
\hline $\begin{array}{c}\text { Primary Health Care } \\
\text { Provider }\end{array}$ & 9 & 82 & 4 \\
\hline $\begin{array}{c}\text { Other Doctor/Physician } \\
\text { (Not Primary Health } \\
\text { Care Provider) }\end{array}$ & 5 & 86 & 3 \\
\hline Pharmacist & 0 & 92 & 1 \\
\hline $\begin{array}{c}\text { Nurse or Care Aid } \\
\text { Friend or Family } \\
\text { Member }\end{array}$ & 6 & 88 & 1 \\
\hline
\end{tabular}


Table 2. Type of advertisements seen by participants $(\mathrm{N}=95)$

\begin{tabular}{|c|c|c|c|}
\hline & Advertisement Seen & Advertisement Not Seen & Not Sure \\
\hline $\begin{array}{c}\text { Doctors Office or } \\
\text { Hospital }\end{array}$ & 12 & 76 & 7 \\
\hline Television & 17 & 70 & 6 \\
\hline $\begin{array}{c}\text { Newspapers or } \\
\text { Magazines }\end{array}$ & 4 & 85 & 4 \\
\hline Internet & 4 & 86 & 6 \\
\hline Recreational Centers & 3 & 89 & 4 \\
\hline Bus or Train & 2 & & \\
\hline
\end{tabular}

Table 3. Results of inferential data $(\mathrm{N}=99)$

\begin{tabular}{|c|c|c|c|}
\hline $\mathrm{Ho}$ and $\mathrm{Ha}$ & Test Used & Result & Conclusion \\
\hline $\begin{array}{l}\text { Ho: There is no association } \\
\text { between vaccination status and } \\
\text { number of visits to primary health } \\
\text { care provider in the past year } \\
\text { Ha: There is an association between } \\
\text { vaccination status and number of } \\
\text { visits to primary health care } \\
\text { provider in the past year }\end{array}$ & $\begin{array}{l}\text { Chi Square } \\
\text { Test } \\
\text { Alpha }=0.05 \\
\text { (Only includes } \\
\text { individuals } \\
\text { aged } 65 \text { and } \\
\text { older } \mathrm{N}=22 \text { ). }\end{array}$ & $\begin{array}{l}\mathrm{P}=0.14905 \\
\text { Rationale: Elderly } \\
\text { population are eligible } \\
\text { for free vaccination } \\
\text { and tend to go to the } \\
\text { doctors more as they } \\
\text { age compared to } \\
\text { people aged 21-64. }\end{array}$ & $\begin{array}{l}\text { Do not reject Ho and } \\
\text { conclude that there is no } \\
\text { association between } \\
\text { vaccination status and } \\
\text { number of visits to } \\
\text { primary health care } \\
\text { provider in the past year. }\end{array}$ \\
\hline $\begin{array}{l}\text { Ho: There is no association } \\
\text { between vaccination status and } \\
\text { primary health care provider } \\
\text { recommendation for the } \\
\text { pneumococcal vaccine } \\
\text { Ha: There is an association between } \\
\text { vaccination status and primary } \\
\text { health care provider } \\
\text { recommendation for the } \\
\text { pneumococcal vaccine }\end{array}$ & $\begin{array}{l}\text { Chi Square } \\
\text { Test } \\
\text { Alpha=0.05 } \\
\text { (Only includes } \\
\text { individuals } \\
\text { aged } 65 \text { and } \\
\text { older } \mathrm{N}=22 \text { ) }\end{array}$ & $\mathrm{P}=0.00118$ & $\begin{array}{l}\text { Reject Ho and conclude } \\
\text { that there is an } \\
\text { association between } \\
\text { vaccination status and } \\
\text { primary health care } \\
\text { provider } \\
\text { recommendation for the } \\
\text { pneumococcal vaccine. }\end{array}$ \\
\hline
\end{tabular}




\begin{tabular}{|c|c|c|c|}
\hline Ho and Ha & Test Used & Result & Conclusion \\
\hline $\begin{array}{l}\text { Ho: There is no association } \\
\text { between number of visits to } \\
\text { primary health care provider and } \\
\text { primary health care provider } \\
\text { recommendation for the } \\
\text { pneumococcal vaccine } \\
\text { Ha: There is an association between } \\
\text { number of visits to primary health } \\
\text { care provider and primary health } \\
\text { care provider recommendation for } \\
\text { the pneumococcal vaccine }\end{array}$ & $\begin{array}{l}\text { Chi Square } \\
\text { Test } \\
\text { Alpha }=0.05 \\
\text { (Only include } \\
\text { individuals } \\
\text { aged } 65 \text { and } \\
\text { older } \mathrm{N}=22 \text { ) }\end{array}$ & $\mathrm{P}=0.25616$ & $\begin{array}{l}\text { Do not reject Ho and } \\
\text { conclude that there is no } \\
\text { association between } \\
\text { number of visits to } \\
\text { primary health care } \\
\text { provider and primary } \\
\text { health care provider } \\
\text { recommendation for the } \\
\text { pneumococcal vaccine. }\end{array}$ \\
\hline $\begin{array}{l}\text { Ho: There is no difference in } \\
\text { number of advertisement types seen } \\
\text { for vaccinated, not vaccinated and } \\
\text { unknown vaccination status } \\
\text { individuals } \\
\text { Ha: There is a difference in number } \\
\text { of advertisement types seen for } \\
\text { vaccinated, not vaccinated and } \\
\text { unknown vaccination status } \\
\text { individuals }\end{array}$ & $\begin{array}{l}\text { ANOVA (one- } \\
\text { way) } \\
\& \\
\text { Post Hoc Tests } \\
\text { Alpha }=0.05 \\
\text { (Only include } \\
\text { individuals } \\
\text { aged } 65 \text { and } \\
\text { older } \mathrm{N}=21 \text { ) }\end{array}$ & $\begin{array}{l}\text { Vaccinated is different } \\
\text { from not vaccinated } \\
\text { and unknown status } \\
\text { Not vaccinated is } \\
\text { different from } \\
\text { vaccinated knowledge } \\
\text { Unknown status is } \\
\text { different from } \\
\text { vaccinated } \\
\mathrm{P}=0.01085 \\
\text { Power }=0.78889\end{array}$ & $\begin{array}{l}\text { Reject Ho and conclude } \\
\text { that there is a difference } \\
\text { in number of } \\
\text { advertisement types seen } \\
\text { for vaccinated, not } \\
\text { vaccinated and unknown } \\
\text { vaccination status } \\
\text { individuals. Vaccinated } \\
\text { individuals appear to } \\
\text { have seen more } \\
\text { advertising types. }\end{array}$ \\
\hline
\end{tabular}

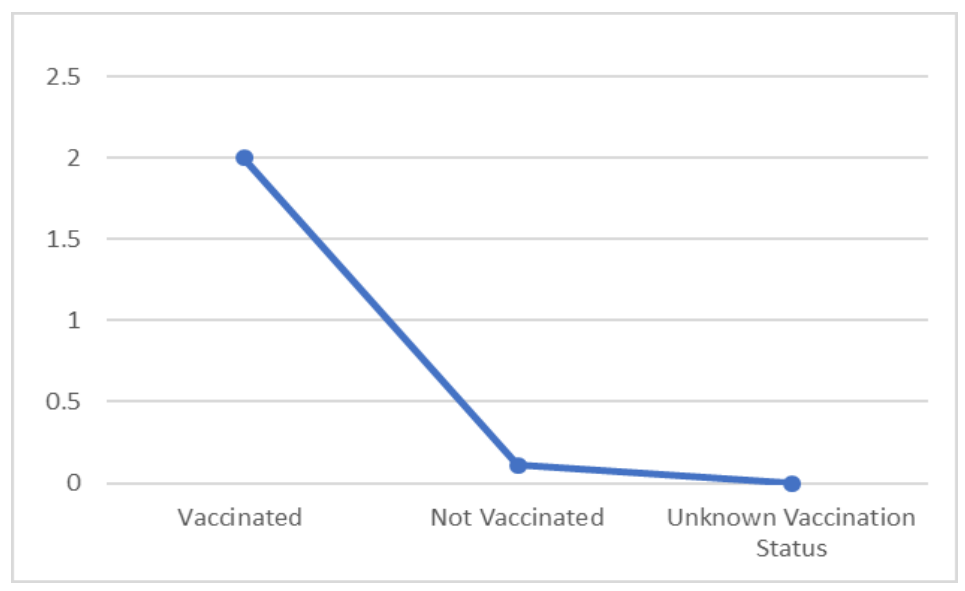

Figure 4. Mean values for ANOVA analysis of difference in number of advertisements seen for individuals who are vaccinated, not vaccinated or have an unknown vaccination status 
Table 4. Results of inferential data ( $\mathrm{N}=99$ total)

\begin{tabular}{|c|c|c|c|}
\hline $\mathrm{Ho}$ and $\mathrm{Ha}$ & Test Used & Result & Conclusion \\
\hline $\begin{array}{l}\text { Ho: There is no association } \\
\text { between knowledge on the } \\
\text { pneumococcal vaccine and primary } \\
\text { health care provider } \\
\text { recommendation for the vaccine } \\
\text { Ha: There is an association between } \\
\text { knowledge on the pneumococcal } \\
\text { vaccine and primary health care } \\
\text { provider recommendation for } \\
\text { vaccination }\end{array}$ & $\begin{array}{l}\text { Chi Square } \\
\text { Test } \\
\text { Alpha }=0.05 \\
\text { (All ages } \\
\text { included } \mathrm{N}=99 \text { ) }\end{array}$ & $\mathrm{P}=0.46671$ & $\begin{array}{l}\text { Do not reject Ho and } \\
\text { conclude that there is no } \\
\text { association between } \\
\text { knowledge on the } \\
\text { pneumococcal vaccine } \\
\text { and primary health care } \\
\text { provider } \\
\text { recommendation for the } \\
\text { vaccine. }\end{array}$ \\
\hline $\begin{array}{l}\text { Ho: There is no association } \\
\text { between knowledge on the } \\
\text { pneumococcal vaccine and } \\
\text { vaccination status } \\
\text { Ha: There is an association between } \\
\text { knowledge on the pneumococcal } \\
\text { vaccine and vaccination status }\end{array}$ & $\begin{array}{l}\text { Chi Square } \\
\text { Test } \\
\text { Alpha }=0.05 \\
\text { (All ages } \\
\text { included } \mathrm{N}=99 \text { ) }\end{array}$ & $\mathrm{P}=0.03920$ & $\begin{array}{l}\text { Reject Ho and conclude } \\
\text { that there is an } \\
\text { association between } \\
\text { knowledge on the } \\
\text { pneumococcal vaccine } \\
\text { and vaccination status. }\end{array}$ \\
\hline $\begin{array}{l}\text { Ho: There is no difference in } \\
\text { knowledge on the pneumococcal } \\
\text { vaccine for individuals who are } \\
\text { vaccinated, not vaccinated or have } \\
\text { an unknown vaccination status* } \\
\text { Ha: There is a difference in } \\
\text { knowledge on the pneumococcal } \\
\text { vaccine for individuals who are } \\
\text { vaccinated, not vaccinated and have } \\
\text { an unknown vaccination status* }\end{array}$ & $\begin{array}{l}\text { ANOVA (one- } \\
\text { way) } \\
\& \\
\text { Post-Hoc Tests } \\
\text { Alpha }=0.05 \\
\text { (All ages } \\
\text { included } \mathrm{N}=99 \text { ) }\end{array}$ & $\begin{array}{l}\text { Vaccinated knowledge } \\
\text { is different from not } \\
\text { vaccinated and } \\
\text { unknown status } \\
\text { knowledge } \\
\text { Not vaccinated } \\
\text { knowledge is different } \\
\text { from vaccinated } \\
\text { knowledge } \\
\text { Unknown status } \\
\text { knowledge is different } \\
\text { from vaccinated } \\
\text { knowledge } \\
\mathrm{P}=0.01085 \\
\text { Power }=0.78889\end{array}$ & $\begin{array}{l}\text { Reject Ho and conclude } \\
\text { that there is a difference } \\
\text { in knowledge on the } \\
\text { pneumococcal vaccine } \\
\text { for vaccinated } \\
\text { individuals compared to } \\
\text { unvaccinated or } \\
\text { unknown vaccination } \\
\text { status individuals. } \\
\text { Vaccinated individuals } \\
\text { appear to have more } \\
\text { knowledge on the } \\
\text { pneumococcal vaccine } \\
\text { than either of the other } \\
\text { groups. }\end{array}$ \\
\hline
\end{tabular}




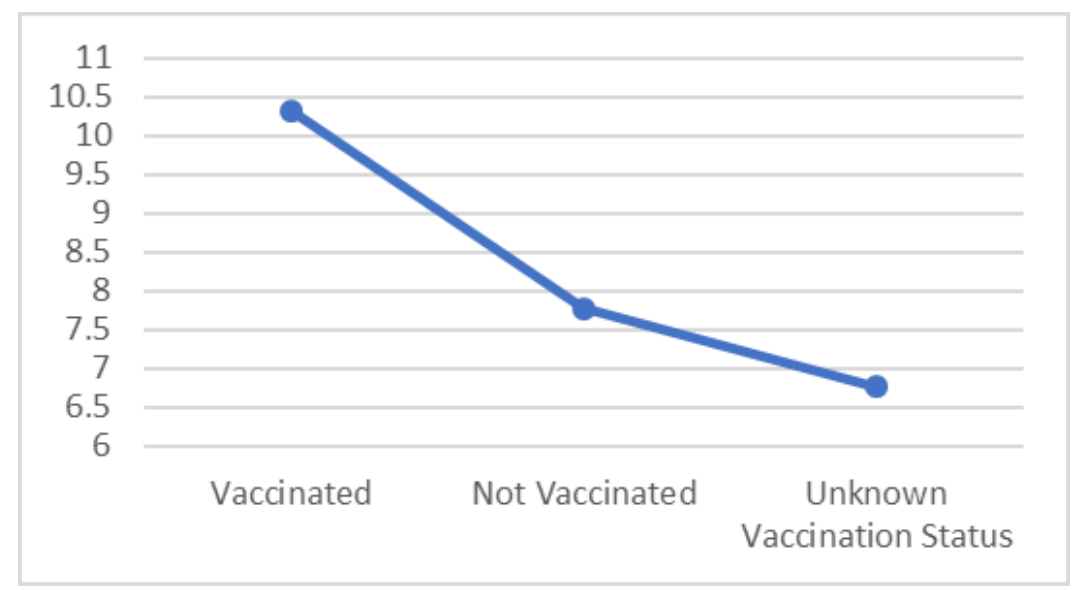

Figure 5. Mean values for ANOVA analysis of difference in knowledge on the pneumococcal vaccine for individuals who are vaccinated, not vaccinated or have an unknown vaccination status

\section{DISCUSSION:}

This study focused on the knowledge and vaccination status of its participants for the 23-valent pneumococcal polysaccharide vaccine. The chi-squared and ANOVA analysis regarding the knowledge of its participants and their vaccination status produced similar results. It can be concluded that individuals who were vaccinated had more knowledge on the pneumococcal vaccine than individuals who were not vaccinated or who had an unknown vaccination status. Another chi-squared analysis was used to determine the association between knowledge of the vaccine and primary health care provider recommendation for the vaccine. No association between recommendation and knowledge was found, contrary to studies analyzed in the literature review. $(7,12,13,18-$ 23) These results suggest that health care providers are not giving patients enough information about the pneumococcal disease or the vaccine when they recommended it to them. Vaccinated participants may have gained their knowledge from primary health care providers, nurses, pharmacists, friends, family or online resources after they received the vaccine. In contrast, these results could also suggest that individuals with more knowledge on pneumococcal disease prior to vaccination are more likely to get vaccinated in the future. No previously conducted studies have looked at the association between vaccination status and knowledge of the pneumococcal vaccine, so more data is needed to confirm these findings.

Using a chi-squared analysis, an association was also found between vaccination status and primary health care provider recommendation for the pneumococcal vaccine. This indicates that with a recommendation from a primary health care provider, individuals are more likely to get vaccinated. These results are consistent with results found in previously conducted studies; one of the most influential predictors of pneumococcal vaccination is recommendation by a general practitioner or family physician. $(13,14,18-24)$ By implementing vaccination programs that involve primary health care providers, vaccination rates can be increased.

Two more chi-squared analyses were conducted to determine the association between vaccination status, number of visits to primary health care provider in the past year and recommendation for vaccination by the primary health care provider. No association was found between vaccination status and number of visits to a primary health care provider. There was also no association found between number of visits and primary health care provider recommendation. These results suggest that 
health care providers are missing opportunities to recommend the vaccine to patients. This is consistent with results found in the reviewed pneumococcal vaccination studies.

$(4,12,13,21,22)$ Practitioners may not recommend the vaccine to their patients because they are more concerned about immediate health problems, they perceive the risk of pneumococcal disease to be low, they do not know the vaccination status of the individual, they lack knowledge on the vaccine, they are concerned about negative side effects, or they believe that the efficacy of the vaccine is too low. $(4,12,13,21,22)$

Lastly, an ANOVA and Post Hoc analysis was conducted to determine if there was a difference in number of advertisement types seen for individuals who were vaccinated, not vaccinated or had an unknown vaccination status. These results have shown that participants who saw more advertisement types were more likely to be vaccinated, which is consistent with studies analyzed in the literature review. $(13,14,18-24)$ The majority of advertisements seen in this survey were on television, but there were also a few advertisements seen in doctors' offices, hospitals, the internet, newspapers or magazines, recreational centers and on buses or trains. Since advertisements were associated with an improved vaccination uptake, more advertisements should be implemented in vaccination programs.

Individuals over 65 who were currently eligible to receive the pneumococcal vaccine for free were the focus of this study, but it also included individuals from 21-65. By broadening the inclusion criteria for the age of participants, educational tools and programs could potentially be extended to those who may receive the vaccine in the future. The pneumococcal vaccine is also available free to individuals who have comorbid diseases or are immunocompromised and these people were represented within all age groups. Both vaccinated and unvaccinated individuals were asked to participate, therefore the results were representative of the general population.

\section{RECOMMENDATIONS AND KNOWLEDGE TRANSLATION:}

There are various methods that would increase vaccination rates in the elderly. Personal contact and discussion is the most successful method of persuasion, so patient outreach programs and vaccinations in nontraditional settings such as bingo halls and churches would allow the elderly to learn more about pneumococcal disease in a comfortable, convenient setting. $(14,23)$ Indirect methods of advertisement such as mailed reminders, posters, brochures and endorsements may also increase vaccination rates. Since the majority of individuals who receive this vaccine are aged 65 or older, advertisements should be placed in public gathering places, magazines and newspapers, on cable television and in health care facilities. Posters in clinic waiting rooms or high volume areas such as malls will be seen much more frequently by elderly individuals who visit them. Clinics can also increase vaccination rates by becoming mobile and visiting more isolated places such as reservations, prisons or elderly living facilities. $(14,23)$ Clinics can also implement a computerized patient vaccination reminder system, give the pneumovax vaccine at the same time as the influenza vaccine and monitor rates of vaccination specific to that clinic. Primary health care providers should also be required to recommend the vaccine to elderly or immunocompromised patients and provide adequate information on pneumococcal disease. According to studies found in the literature review and the results of this study, primary health care provider recommendation and number of advertisements seen significantly influences an individuals choice to get the pneumococcal vaccination. $(13,14,18-24)$ The results of this study may also be used in future publications on pneumococcal disease, vaccination, advertising and allocation of health care funding by government officials. To break down the barriers that prevent vaccination, education and public health initiatives involving primary health care providers and public advertisements should be implemented to increase vaccination rates. 


\section{LIMITATIONS:}

There were multiple limitations to this survey study. For example, participants dropped out during the survey which created incomplete responses. These responses made the sample size inconsistent for different graphs and tables and may have caused a type II or beta error. A type I or alpha error may have also occurred since an alpha value of 0.05 was used for statistical significance analyses. Selection bias was another limitation of this study. Firstly, there was a small number of participants aged 65 and older compared to the other age categories. Also, there was a small number of participants from some provinces in Canada. Therefore, the results of this survey may not be representative of the entire country. Multiple methods were also used to collect survey responses which may have affected internal validity of the study. The survey questions themselves may have been open to subjective interpretation and some participants may have entered personal information such as vaccination status incorrectly. Since the survey was available online, participants may have looked answers up online or guessed at the correct answers. Lastly, results from this study may not be used for other vaccines since the questions were specific to the pneumococcal vaccine.

\section{FUTURE RESEARCH:}

Additional long-term meta-analyses and epidemiological studies are needed to determine the efficacy of the pneumococcal vaccine. Also, the social determinants of vaccination status need to be found and addressed to create targeted public health initiatives. Primary health care providers should also be surveyed to determine if they are recommending the pneumococcal vaccine. This survey should also determine when a recommendation would be made to a patient.

\section{CONCLUSION:}

Pneumococcal disease is an opportunistic infection that can cause multiple severe and painful symptoms which can eventually lead to death. Currently, immunocompromised individuals and elderly individuals aged 65 and older have the option to be vaccinated against this disease free of charge in Canada. Since the risk of infection can be reduced by an available vaccine, more public health initiatives should be implemented to increase vaccination rates and reduce possible antibiotic resistance, death and associated health care costs. These initiatives should focus on educating the elderly as well as promoting recommendation by physicians for the vaccine. More research needs to be done on the efficacy of the vaccine, but since no detrimental side effects have been observed, it should be promoted and advertised to those who are at an increased risk of infection.

\section{COMPETING INTERESTS}

The authors declare that they have no competing interests

\section{REFERENCES:}

1. Office Auditor General of British Columbia. Health funding explained [Internet]. Victoria, BC. 2016. Available from: http://www.bcauditor.com/healthfundingexplained

2. Government of Canada. Canadian immunization guide: Part 4- Active vaccines [Internet]. 2016 [cited 2016 Oct 16]. Available from: http://healthycanadians.gc.ca/publications/healthy-living-viesaine/4-canadian-immunization-guide-canadien-immunisation/index-eng.php?page $=16$

3. Government of Canada. Vaccine uptake in Canadian adults: Results from the 2014 adult national immunization coverage survey (aNICS) [Internet]. 2015 [cited 2016 Oct 16]. Available from: http:/healthycanadians.gc.ca/publications/healthy-living-vie-saine/vaccine-coverage-adultsresults-2014-resultats-couverture-vaccinale-adultes/index-eng.php

4. Schneeberg A, Bettinger JA, Mcneil S, Ward BJ, Dionne M, Cooper C, et al. Knowledge, 
attitudes, beliefs, and behaviours of older adults about pneumococcal immunization, a Public Health Agency of Canada/Canadian Institutes of Health Research Influenza Research Network (PCIRN) investigation. BMC Public Health [Internet]. 2014;14(442). Available from: http://www.biomedcentral.com/1471-2458/14/442

5. Fraser Health. Fraser health report: Immunizations and vaccine preventable diseases [Internet]. 2015. Available from: http://www.fraserhealth.ca/media/2015-0423_Immunizations_AnnualReport.pdf

6. BC Centre for Disease Control. Immunization in British Columbia [Internet]. Vancouver; 2008. Available from: http://www.bccdc.ca/resource-gallery/Documents/Statistics and Research/Statistics and Reports/Immunization/2008AnnualReportFINALcolour28OCT2010.pdf

7. Drijkoningen JJC, Rohde GGU. Pneumococcal infection in adults: Burden of disease. Clin Microbiol Infect. 2014;20(5):45-51.

8. BC Centre for Disease Control. BC annual summary of reportable disease [Internet]. Vancouver; 2014. Available from: http://www.bccdc.ca/resource-gallery/Documents/Statistics and Research/Statistics and Reports/Epid/Annual Reports/AR2014FinalSmall.pdf

9. Schiffner-Rohe J, Witt A, Hemmerling J, Von Eiff C, Leverkus FW. Efficacy of PPV23 in preventing pneumococcal pneumonia in adults at increased risk: A systematic review and metaanalysis. PLoS One. 2016;11(1).

10. Menzies RI, Jardine A, McIntyre PB. Pneumonia in elderly Australians: Reduction in presumptive pneumococcal hospitalizations but no change in all-cause pneumonia hospitalizations following 7valent pneumococcal conjugate vaccination. Clin Infect Dis. 2015;61(6):927-33.

11. De Soárez PC, Sartori AMC, Freitas AC, Nishikawa ÁM, Novaes HMD. Cost-effectiveness analysis of universal vaccination of adults aged 60 years with 23 -valent pneumococcal polysaccharide vaccine versus current practice in Brazil. PLoS One. 2015;10(6).

12. Sabapathy D, Strong D, Myers R, Li B, Quan H. Pneumococcal vaccination of the elderly during visits to acute care providers: Who are vaccinated? Prev Med (Baltim). 2014;62:155-60.

13. Krueger P, Loeb M, Kelly C, Edward HG. Assessing, treating and preventing community acquired pneumonia in older adults: Findings from a community-wide survey of emergency room and family physicians. BMC Fam Pract. 2005;6(32).

14. Prevention C for DC and. Adult immunization programs in nontraditional settings : Quality standards and guidance for program evaluation. Morb Mortal Wkly Rep. 2000;49(1).

15. Moore R., Wiffen P., Lipsky B. Are the pneumococcal polysaccharide vaccines effective: Metaanalysis of the prospective trials. BMC Fam Pract. 2000;1(1).

16. Ochoa-Gondar O, Vila-Corcoles A, Rodriguez-Blanco T, Gomez-Bertomeu F, Figuerola-Massana E, Raga-Luria X, et al. Effectiveness of the 23-valent pneumococcal polysaccharide vaccine against community-acquired pneumonia in the general population aged greater than or equal to 60 years: 3 years of follow-up in the CAPAMIS study. Clin Infect Dis. 2014;58(7):909-17.

17. Huss A, Scott P, Stuck AE, Trotter C, Egger M. Efficacy of pneumococcal vaccination in adults: A meta-analysis. CMAJ. 2009;180(1):48-58.

18. Krueger P, Amant OS, Loeb M. Predictors of pneumococcal vaccination among older adults with pneumonia: findings from the Community Acquired Pneumonia Impact Study. BMC Geriatr [Internet]. 2010;10(44). Available from: http://www.biomedcentral.com/1471-2318/10/44 
19. Kyaw MH, Greene CM, Schaffner W, Ray SM, Shapiro M, Barrett NL, et al. Adults with invasive pneumococcal disease: Missed opportunities for vaccination. Am J Prev Med. 2006;31(4):286-92.

20. Klett-Tammen CJ, Krause G, Seefeld L, Ott JJ, De H. Determinants of tetanus, pneumococcal and influenza vaccination in the elderly: A representative cross-sectional study on knowledge, attitude and practice (KAP). BMC Public Health. 2016;16(121).

21. Klett-Tammen CJ, Krause G, Von Lengerke T, Castell S, De H. Advising vaccinations for the elderly: A cross-sectional survey on differences between general practitioners and physician assistants in Germany. BMC Fam Pract. 2016;17(98).

22. Eilers R, Krabbe PFM, De Melker HE. Attitudes of Dutch general practitioners towards vaccinating the elderly: Less is more? BMC Fam Pract. 2015;16(158).

23. Lau D, Hu J, Majumdar S, Storie D, Rees S, Johnson J. Interventions to improve influenza and pneumococcal vaccination rates among community-dwelling adults: A systematic review and meta-analysis. Ann Fam Med. 2012;10:538-46.

24. Gorska-Ciebiada M, Saryusz-Wolska M, Ciebiada M, Loba J. Pneumococcal and seasonal influenza vaccination among elderly patients with diabetes. Postep Hig Med Dosw [Internet]. 2015;69(69):1182-9. Available from: www.phmd.pl

25. Survey Monkey [Internet]. San Mateo, California, USA, 2017. Available from https://www.surveymonkey.net

26. NCSS 11 Statistical Software. NCSS, LLC [Internet]. Kaysville, Utah, USA; 2011. Available from: ncss.com/software/ncss

27. Microsoft Excel [computer software]. 2017. Available from https://www.microsoft.com/en-ca/

28. Microsoft Word [computer software]. 2017. Available from https://www.microsoft.com/en-ca/

29. Google Docs Online [computer software]. Santana Clara County, California, USA: 2011.

Available from https://www.google.ca/docs/about/. 